\title{
Service Design for Accessible Tourism
}

\author{
Hans-Peter Hutter ${ }^{1}$, Alireza Darvishy ${ }^{1}$, Stephan Roth ${ }^{1}$, Susanne Gäumann ${ }^{2}$, Heidi Kas- \\ par $^{3}$, Tatjana Thimm ${ }^{4}$, Maksym Gaiduk ${ }^{5}$, Sandra Evans ${ }^{6}$, Martin Rosenberg ${ }^{7}$ \\ ${ }^{1}$ InIT Institute of Applied Information Technology, \\ ZHAW Zurich University of Applied Sciences, Switzerland \\ hans-peter.hutter@zhaw.ch \\ ${ }^{2}$ Claire\&George Stiftung, Berne, Switzerland \\ kontakt@claireundgeorge.ch \\ ${ }^{3}$ Careum Hochschule Gesundheit, \\ Fachhochschule Kalaidos, Zürich, Switzerland \\ heidi.kasparecareum-hochschule.ch \\ ${ }^{4}$ Fakultät Wirtschafts-, Kultur- und Rechtswissenschaften, \\ HTWG Konstanz, Konstanz, Deutschland \\ tthimmahtwg-konstanz.de \\ ${ }^{5}$ Ubiquitous Computing Lab, \\ HTWG Konstanz, Konstanz, Deutschland \\ maksym.gaiduk@htwg-konstanz . de \\ ${ }^{6}$ LebensPhasenHaus, \\ Eberhard Karls Universität Tübingen, Deutschland \\ sandra.evans@ipc.uni-tuebingen.de \\ ${ }^{7}$ NESTOR Intl. Corp. AG, Appenzell, Switzerland \\ martin.rosenberg@nestor-swiss.ch
}

\begin{abstract}
This paper presents the goals, service design approach, and the results of the project "Accessible Tourism around Lake Constance", which is currently run by different universities, industrial partners and selected hotels in Switzerland, Germany and Austria. In the $1^{\text {st }}$ phase, interviews with different persons with disabilities and elderly persons have been conducted to identify the barriers and pains faced by tourists who want to spend their holidays in the region of Lake Constance as well as possible assistive technologies that help to overcome these barriers. The analysis of the interviews shows that one third of the pains and barriers are due to missing, insufficient, wrong or inaccessible information about the accessibility of the accommodation, surroundings, and points of interests during the planning phase of the holidays. Digital assistive technologies hence play a major role in bridging this information gap. In the $2^{\text {nd }}$ phase so-called Hotel-Living-Labs (HLL) have been established where the identified assistive technologies can be evaluated. Based on these HLLs an overall service for accessible holidays has been designed and developed. In the last phase, this service has been implemented based on the HLLs as well as the identified assistive technologies and is currently field tested with tourists with disabilities from the three participated countries.
\end{abstract}

Keywords: Accessible Tourism, Service Design. 


\section{Introduction}

\subsection{Accessible Tourism}

For more than 30 years, accessible tourism has been discussed in many countries and international organizations are working on global standards for assessible tourism for all [1],[2]. Different associations have developed guidelines for hotels and other service providers in tourism on how to best deal with tourists with disabilities, e.g. [3-6]. These guidelines are written from perspective of the hotel service provider and therefore mainly focus on the holiday journey steps from the arrival of the guests until their departure. Tourists with disabilities and elderly tourists, however, face many additional pains and barriers while planning and booking their holidays and while travelling to the hotel destination and back home. The Project "Accessible Tourism around Lake Constance" (in German, Barrierefreier Tourismusraum Bodensee, or BTB) presented in this paper took the perspective of guests with disabilities from the very beginning and also considered the journey steps before and after the actual holiday trip.

\subsection{Project BTB}

The project BTB started in March 2018 and lasts until October 2020. It is part of the IBH Living Labs AAL and has a specific focus on lowering the barriers for tourists with disabilities, specifically in the Lake Constance region. The main goals of this project are

- to identify the barriers tourists with disabilities still face when they want to spend holidays in general and specifically in the region of Lake of Constance

- to identify possible assistive technologies and services to overcome these barriers

- to develop a holistic service for accessible holidays based on so-called Hotel-LivingLabs (HLLs). HLL are guestrooms in generally accessible hotels that are equipped with specific assistive technologies.

The service for accessible holidays was developed according to the new service development process ISDP proposed in [7] and depicted in Fig. 1.

The remaining sections of the paper will present and discuss mainly the results of the first two phases "Customer and Context Analysis>" and "Service Innovation" as well as first insights of the other phases. 


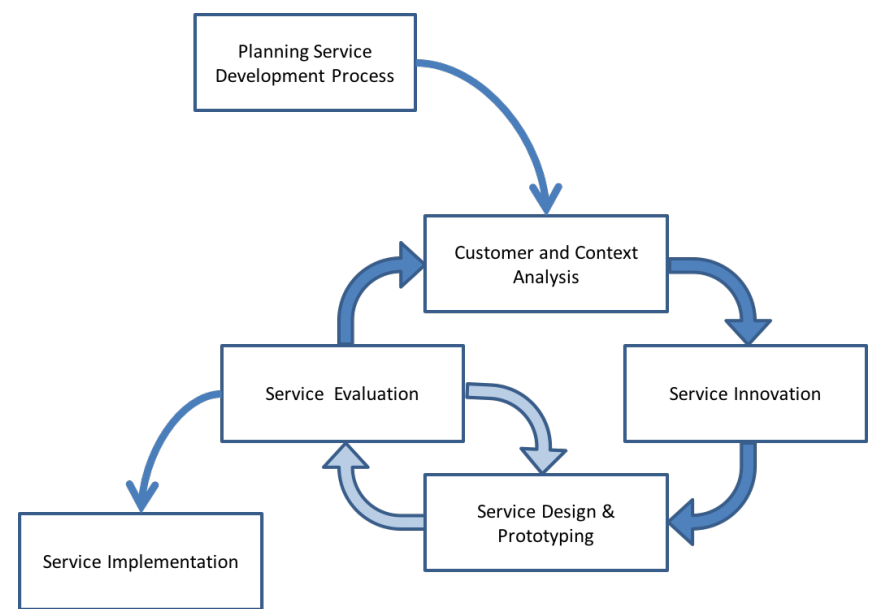

Fig. 1. InIT Service Development Process (ISDP)

\section{Customer and Context Analysis}

In this user research phase, 32 semi-structured interviews were conducted in Switzerland and Germany with people from the following tourist groups:

- Tourists using wheelchairs or with impaired mobility (10)

- Tourists with visual impairments (5)

- Tourists with hearing impairments (2)

- Tourists with cognitive disabilities (7)

- Elderly tourists with assistive needs (8)

In addition, one group of tourists was interviewed together with their care givers who organize the holiday trips for the whole group. Almost one third of all interviewed persons are retired and more than one third need or prefer to have an accompanying person with them during their holidays.

Nearly all participants stated that a very detailed planning, organization, and validation of all aspects of their holidays is very crucial to them as an adaptation of the plan during the holidays is normally very arduous.

The first part of the interviews comprised general questions about the persons and their holidays, the second part of the interviews was structured along the Customer Journey Map for holiday trips depicted in Fig. 2. This Customer Journey Map was developed by the project partners based on the Universal Job Map from [8]. 


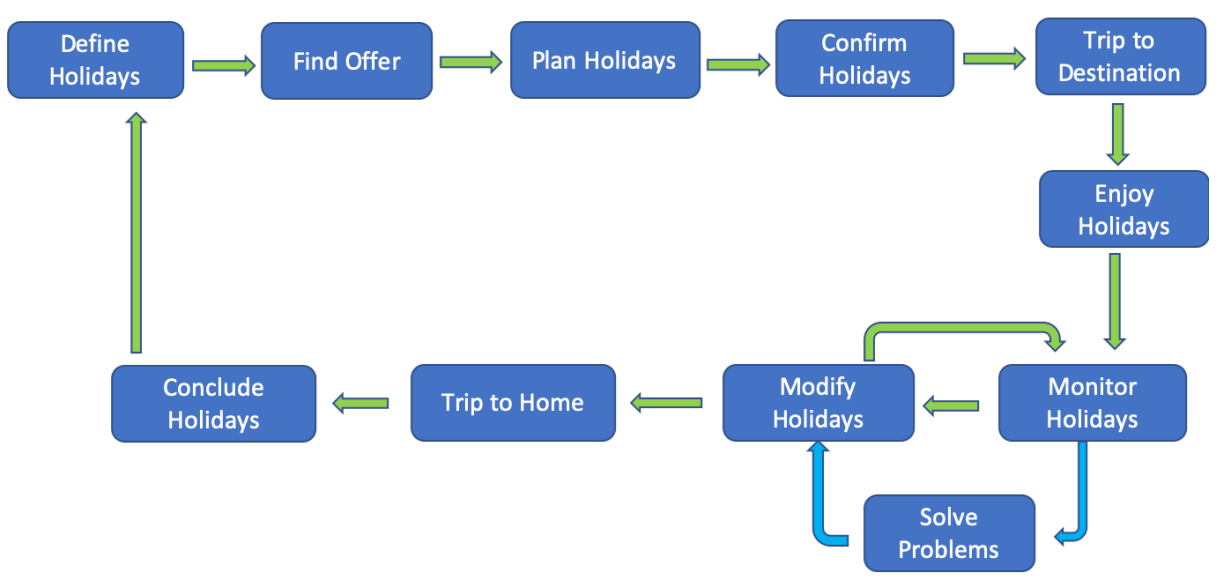

Fig. 2. Customer Journey Map of Holidays

\section{Service Innovation}

In this phase, the entire customer journeys of the above tourist groups were scrutinized based on the interviews, starting with the determination of the goal and destination of the holidays, through the planning, the journey to the destination and back, the stay at the destination (including indoor and outdoor activities) until the conclusion of the holidays and the reimbursement by the health insurance providers.

\subsection{Pains and Barriers Guests with Disabilities Face on their Holidays}

The interviewed tourists with disabilities mentioned 203 barriers or pains they face during their holidays (Fig. 3). With 36\% the majority of barriers mentioned in the interviews are related to information that is missing, insufficient, wrong or not accessible to them. $25 \%$ of the mentioned barriers or pains are related to the travel from home to the destination and back, most of them occurring with public transportation. $21 \%$ of the barriers concern the accommodation itself whereas $16 \%$ of the barriers mentioned are occurring during activities outside the accommodation, mainly inaccessible points of interests or inaccessible toilets, but also inaccessible way signs. Among the $2 \%$ remaining pains is the price the most prominent aspect which may become a barrier in some cases. 


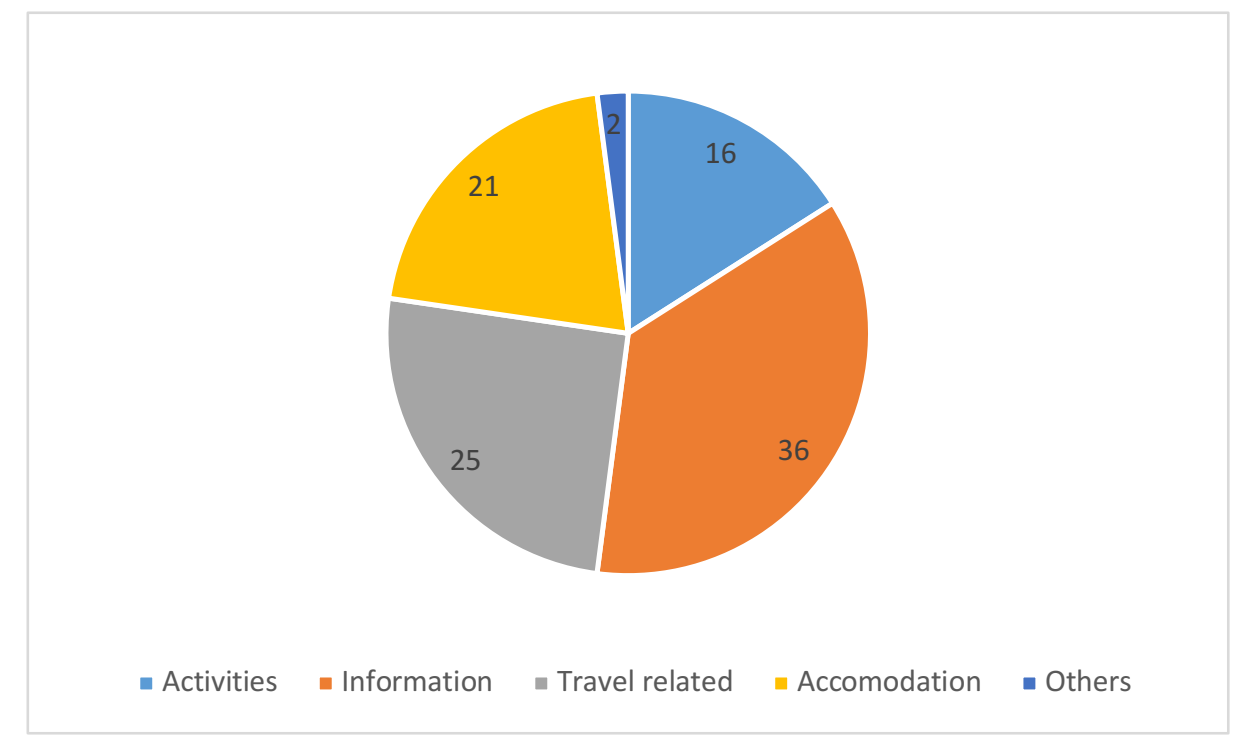

Fig. 3. Major barriers during holiday trips

The first step in the customer journey of the tourists is to define what the goals of their holidays should be. The motivation for holidays was in nearly $20 \%$ of the cases to get to know new things (regions, people, culture), to enjoy the warm climate, and recreation or doing sporting activities. $10 \%$ of the interviewed tourists mentioned "good food" as an important aspect of their holidays.

The next step in the customer journey is to find a suitable offer that meets the tourist's goals and requirements, taking into consideration their specific needs and those of the accompanying persons. In this phase, a lot of detailed information about the accessibility of the accommodation and the surroundings is needed. This information is collected from various sources: $90 \%$ of the interviewed tourists with disabilities rely on the internet to get this information and about $38 \%$ organize their holidays together with a travel agency. $18 \%$ of the interviewed persons rely on recommendations from other persons and less than $10 \%$ use a catalog.

Once suitable offers have been identified, the holiday must be planned in detail (e.g. transport of people, luggage, equipment to the destination, organization of assistive technologies and services needed at the destination, planning of activities and many more things). In this stage, a lot of detailed information about accessibility of the accommodation itself, the surroundings as well as the point of interests is needed. Different associations have developed detailed accessibility checklists for hotels, as e.g. [36], and accessible hotels should provide accessibility information on that level of detail. In addition, pictures of the accessible rooms showing the important details regarding accessibility or even a floor plan with the most important measures would be very helpful during planning.

Still too often this information is missing or not detailed enough so that the prospective guests have to clarify these issues with a phone call to the hotel or through the 
travel agency they booked their holidays, which is a big pain for these guests that can become a barrier. Another big pain in this phase is outdated or wrong accessibility information which becomes a problem only later when the guest is at the hotel and realizes that the provided information is not true.

As can be seen from the accessibility checklists in [3-6], wheel chair users have the most requirements regarding accessibility of an accommodation. Guests with other than mobility impairments have less and less strict requirements regarding accessibility. As a consequence, hotels normally only provide very general accessibility information for these tourist groups. For guests with visual impairments, additional barriers in this stage arise when the information on the websites itself is not accessible or difficult to find and navigate.

The next step in the customer journey, "Confirm Holidays", comprises the confirmation of all bookings and reservations needed. The interviewed people normally like to do the booking of their holidays directly online. However, online booking of accessible hotel rooms is often not possible so that the guests or their travel agency have to call the hotel to do the final booking.

The next step, "Trip to Destination," as well as the step "Trip to Home", may involve many barriers, especially when public transportation is used. One third of the travels to the holiday destination were undertaken with private car and another third with public transportation means. A quarter of the travels were done by airplane. Sometimes also taxis were used at least for parts of the travel.

. Fig. 4 shows that the major pains the interviewed guests with disabilities have regarding their travel to the destination of their holidays and back are emergency situations with the assistive technologies, services or the accompanying person (e.g. no assistance available for changing trains, loss/defect of assistive technologies or luggage), followed by accessibility issues of public transportation means and delays or even cancellations of them. These issues jeopardize the original travel plan and need immediate 
adaptation of the rest of the travel. The major pain of travelers with their private car is the lack of accessible toilets on their way.

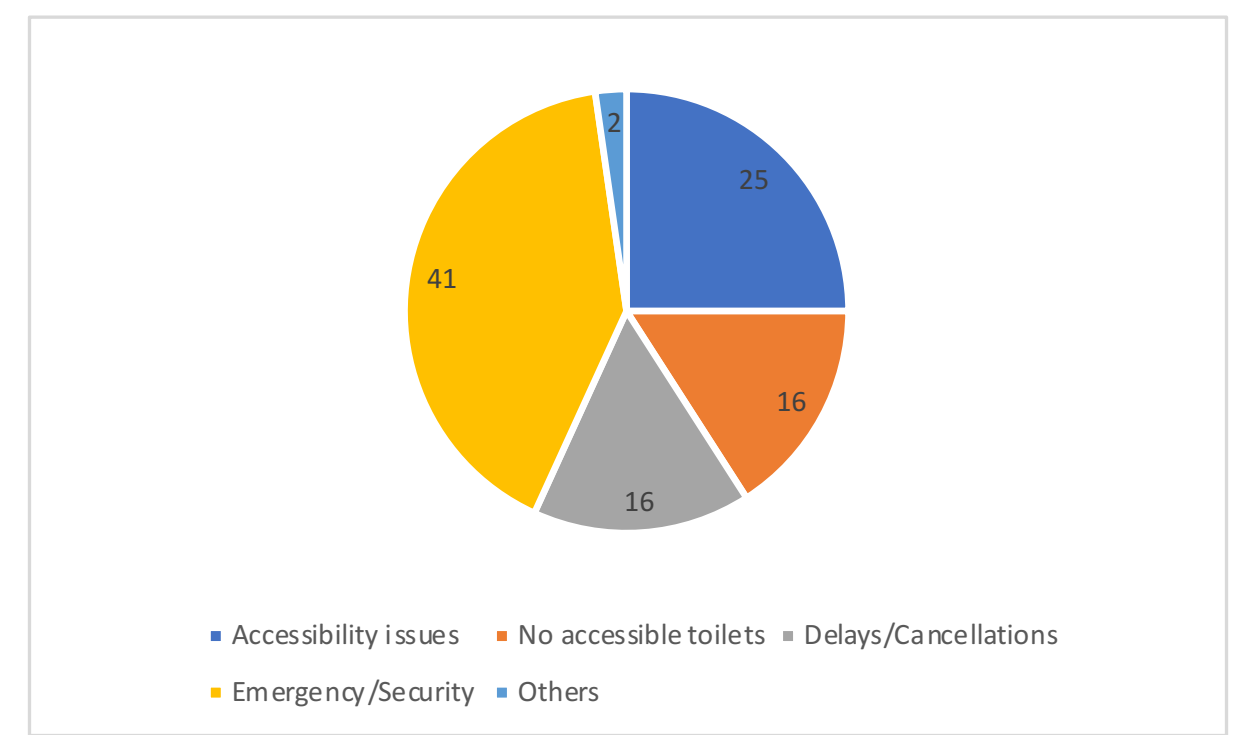

Fig. 4. Major pains regarding travelling to holiday destination

The main step of the whole customer journey is to enjoy the holidays, which comprises not only the standard activities of daily living but also using all indoor and outdoor facilities and services offered by the hotel as well as visits of the surrounding places, points of interests, and events.

Tourists with disability normally choose their accommodation according to accessibility criteria and their special needs. Nevertheless, the most frequently mentioned pains during the holiday stay are accessibility issues with the accommodation (Fig. 5), e.g. too narrow bath rooms or stairs. These accessibility issues normally arise when the corresponding information during planning was missing, inaccurate or wrong, or when the assistive technology provided was not usable, which was mentioned $17 \%$ of the times. Other notable issues were no or not available accessible parking lots, problems with the communication in the hotel (for tourists with hearing impairment), or that the hotel was accessible but not family friendly. 


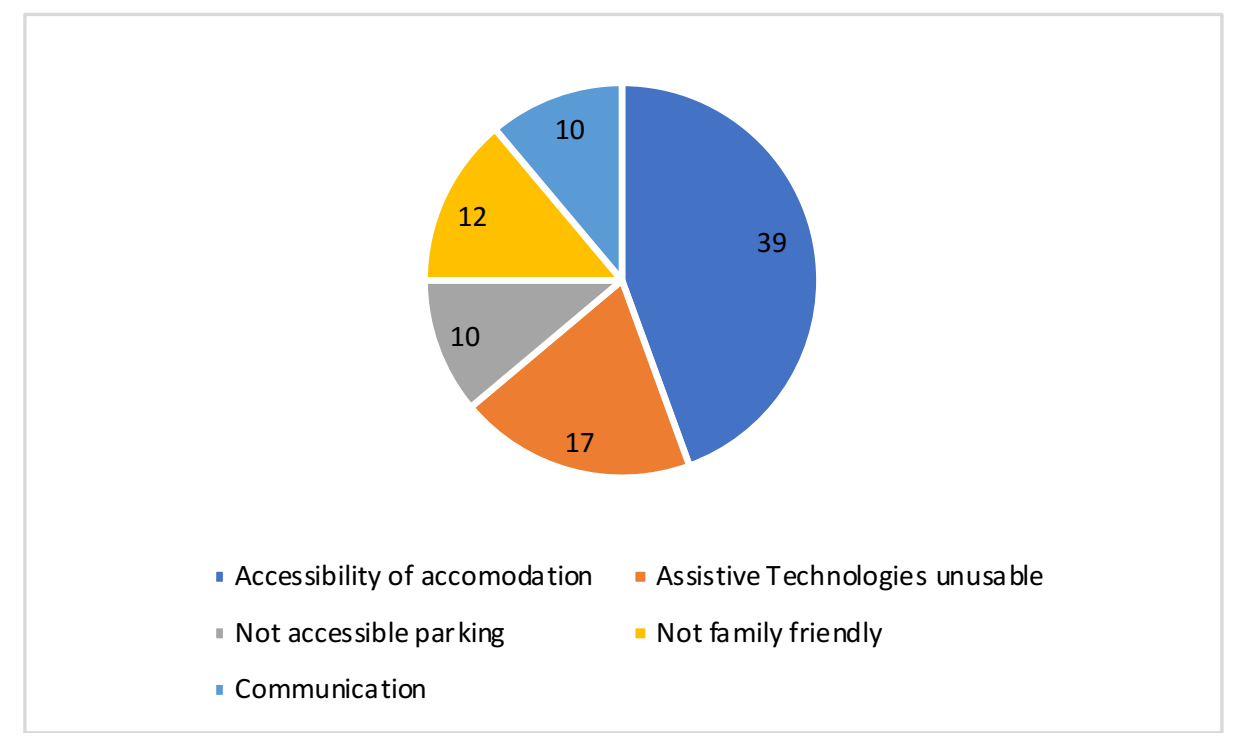

Fig. 5. Major pains regarding the holiday stay

These accessibility issues with the accommodation mean in the best case that the guests have to solve the problem themselves or have to ask the hotel staff for help, e.g., regarding an assistive technology or other facilities in the hotel. In the worst case, these issues require modifications of the holidays, e.g., guests have to change their rooms or even their hotels because it is not accessible for them or is otherwise inadequate.

As can be seen in Fig. 3 16\% percent of the accessibility issues during holidays that were mentioned were related to activities during the holidays. More than half of these issues concern inaccessible points of interests. $2^{\text {nd }}$ most mentions refer to missing assistive services like audio guides or sign language translators, followed by non-barrierfree paths. 


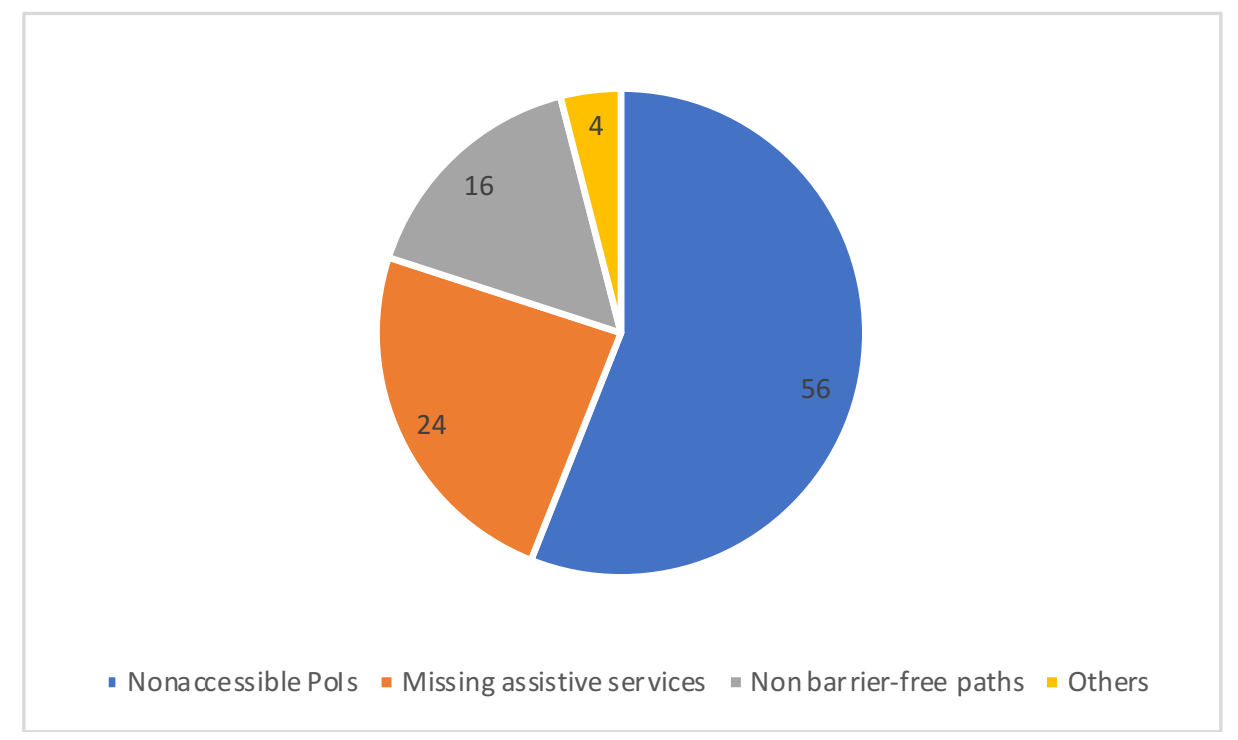

Fig. 6. Accessibility issues during activities

The penultimate step in the holiday journey, the trip to home, has the same accessibility issues as the trip to the holiday destination. The last step, "Conclude Holidays", includes the payment of the holidays as well as the financial reimbursement through insurance providers, but also giving feedback to the hotel and the community about the experiences made. Interestingly, hardly any pains or accessibility issues were mentioned by the interviewed tourists with respect to this last journey step.

\subsection{Assistive Technologies}

When people with disabilities go on holidays, they normally chose their holiday destination according to their needs and they bring their specific assistive technologies with them. This can be a wheel chair, a white cane, a shower chair, or a smartphone with a screen reader and various other apps to support them on their holidays.

As most of the pains and barriers during holidays are due to missing, inaccurate, or inaccessible information in the planning phase of the holidays and on site, the most important assistive technologies for holidays are digital assistive technologies that allow the guests with special needs to find, access and read all information they need in an accessible way for them. Therefore, accessible websites with detailed, accurate and up to date information about the accessibility of accommodations and their infrastructure, their surroundings, nearby points of interest, and activities offered are key for guests with disabilities. Our interviews revealed that most of the pains and barriers occurring during the holidays of guests with disabilities could be avoided if the corresponding information had been available in the planning phase. During their holiday 
trip guests with disabilities normally rely on their smartphones to find and access information about their trip, the infrastructure, the surroundings or points of interests in an accessible way for them.

Based on these insights, the project BTB concentrates on digital assistive technologies to find, access and read accessibility related (and other relevant) information about the accommodation, the infrastructure, the surroundings and the points of interest in an accessible way. On the one hand, these are accessible and easy to use websites of accommodations and other holiday service providers that provide detailed, accurate and up-to-date information for planning the holidays. On the other hand, these are assistive technologies based on smartphones and smartwatches that allow to provide locationbased up-to-date information about infrastructure, activities, points of interest but also about public transportation in an individually accessible way. They also allow for immediate help in emergency situations which is another major pain for tourists with disabilities.

\section{Service Design}

The design of a holistic service for accessible holidays developed within the project BTB is based on so-called Hotel-Living-Labs (HLLs) and covers all steps of a holiday journey (see Fig. 2). HLLs are hotel rooms in generally accessible hotels that are equipped with additional digital assistive technologies in order to address the pains and barriers identified in Section 3.1.

The participating hotels with HLLs are advertised on a specifically designed platform run by a partner of the project. The platform provides detailed information about all accessibility aspects of the accommodations and its surroundings that are needed for a detailed planning of the holiday and this in an accessible way.

The prospective guests also enter all booking details as far as possible on this platform. The booking and confirmation as well as the clarification of remaining questions is done by the booking service run by the same project partner who runs the platform.

Once the booking of the holidays is confirmed, the guest gets a digital documentation of the booked holidays with detailed information about the accommodation, the booked services as well as information about the travel from their home to the booked accommodation.

The guests are provided with a special "Accessible Holidays App" where they can browse the digital holiday information in an accessible way. The app also informs the guests about any updates related to their travel, their accommodation, or booked services. Last but not least, the app offers an emergency button which directly connects the guests to their travel agency which exactly knows what they have booked, their assistance needs, and where they currently are. With this information, the travel agency can organize adequate help for the guests as soon as possible.

The guests are also invited to download the ginto app [9] where they can find information about the accessibility of the points of interest in their surroundings.

They are also provided with a smartwatch with GPS and phone call functionality developed by one of the partners of the project BTB. In case of an emergency, the guests 
can easily call one of the predefined numbers by pressing a button on the smartwatch. If the smartwatch detects a fall or an unconsciousness of the guest the stored numbers are called automatically in the order they have been stored. The called persons also get the GPS coordinates of the smartwatch so that they can easily localize the guest.

Finally, some of the HLLs will be equipped with a voice assistant in the hotel room where the guests can easily ask by voice for information about the accommodation as well as the services offered and the surroundings.

The developed service for accessible holidays will be field tested in April-May 2020 with volunteering guests with different disabilities. First results of this field test are expected to be available at the conference.

\section{$5 \quad$ Conclusion and Outlook}

This paper has summarized the service design approach and results of the project "Accessible Tourism around Lake Constance" who's goals were to identify todays pains and barriers tourists with disabilities experience when they want to spend holidays in the area of Lake Constance. The results so far have shown that the majority of barriers and pains are related to information that is missing, inaccurate, outdated, or not accessible to the guests during their decision making and planning, but also during their holiday stay. The service design for accessible holidays developed in this project therefore concentrates on digital assistive technologies that provide the needed information detailed enough and in an accessible manner in the planning and booking phase as well as during the stay. The designed service is currently field tested based on Hotel-LivingLabs equipped with these digital assistive technologies. The developed service for accessible holidays will be offered by one of the project partners beyond the end of the project.

This project is funded in the context of the IBH Living Lab AAL by Interreg, EU EFRE, and the Swiss Confederation.

\section{References}

[1] World Tourism Organization (UNWTO), Accessible Tourism for All: An Opportunity within Our Reach. World Tourism Organization (UNWTO), 2016.

[2] "Zero Project | For a world without barriers," Zero Project, 13-Feb-2019. [Online]. Available: https://zeroproject.org/. [Accessed: 13-Feb-2019].

[3] "Prüfsystem zur Barrierefreiheit, Version 3.0, Qualitätskriterien.” Deutsches Seminar für Tourismus (DSFT) Berlin e. V., Jan-2019.

[4] "Barrierefreier Tourismus für Alle." ADAC, 2003.

[5] S. Gäumann, hotelleriesuisse, et al., Barrierefreiheit in der Hotellerie. Claire \& George Stiftung, 2018.

[6] Peter, Hans-Karl, "BKB_Handbuch barrierefrei_komplett.pdf." BKB Bundeskompetenzzentrum Barrierefreiheit e. V., Oct-2010.

[7] H.-P. Hutter and A. Ahlenstorf, "New Mobile Service Development Process," in Design, User Experience, and Usability: Designing Pleasurable Experiences, 2017, pp. 221-232, doi: 10.1007/978-3-319-58637-3_17. 
[8] L. A. Bettencourt, Service Innovation. How to Go from Customer Needs to Breakthrough Services. New York: Mc Graw Hill, 2010.

[9] ginto, "Deine zugänglichen Orte," ginto. [Online]. Available: https://www.ginto.guide. [Accessed: 21-Jan-2020]. 